\title{
Linaje, patrimonio y prestigio. La nobleza titulada de la ciudad de Quito en el siglo XVIII
}

\author{
Christian Büschges \\ Universidad de Colonia, Alemania
}

La nobleza colonial, a pesar del esfuerzo pionero de Doris Ladd sobre Nueva España, es todavía un grupo poco conocido en la historia social de América Latina. El presente artículo analiza la realidad social de la nobleza titulada de Quito durante la época colonial tardía, centrándose en el prestigio, el patrimonio y la función que la hicieron aparecer como una parte destacada de la capa social alta, o sea la nobleza, de la ciudad. De una parte, se consideran particularmente la base y las actividades económicas, el ejercicio de empleos y cargos, así como las relaciones de parentesco y su trascendencia socioeconómica; de la otra, se discute la posición de este grupo en la capa alta de la sociedad.

El presente artículo analiza el origen y la posición social de las familias de los diez títulos de Castilla que la ciudad de Quito albergó en la época colonial tardía, o sea entre 1760 y 1810. Eran los Carcelén (marquesado de Villa Rocha), Flores y Quiñones (marquesado de Miraflores), Guerrero (condado de Selva Florida), Jijón (condado de Casa Jijón), Maldonado (marquesado de Lises), Matheu (marquesado de Maenza), Montúfar (marquesado de Selva Alegre), Sánchez de Orellana (marquesados de Solanda y Villa Orellana) y Villavicencio (condado del Real Agrado). ${ }^{1}$ Entre estas mismas familias había, durante el período indicado, trece caballeros de las órdenes nobiliarias españolas, en su mayoría de las órdenes de Santiago y de Carlos III. ${ }^{2}$ Estas familias y sus parientes inmediatos formaron parte de una capa social alta que comprendía en 1789 algo más de 500 personas, o sea un 2,1\% de la población urbana que ascendía en esta época a cerca de 24.000 habitantes. ${ }^{3}$

1 Esta lista de apellidos se limita a los varones de los titulares.

2 Entre las otras familias radicadas constantemente en la ciudad de Quito sólo hay hasta 1810 un caballero de hábito, Fernando Bustamante. Entre 1814 y 1822 otros dos miembros de las familias estudiadas recibieron el hábito de la orden de Carlos III. Además, en el mismo período, fueron concedidos dos hábitos de la Real Orden Americana de Isabel la Católica; los beneficiados fueron miembros de las familias quiteñas de los Calisto y de los Chiriboga.

3 Acerca del concepto de nobleza y de la diferenciación nobiliaria en Quito véase Büschges, Christian: "Nobleza y estructura estamental entre concepto y realidad social. El caso de la ciudad de Quito y su región (1765-1810)", Jahrbuch für Geschichte von Staat, Wirtschaft und Gesellschaft Lateinamerikas, 33, Colonia, Viena y Weimar, 1996, págs. 165-186. 
Junto a estas familias la capa social alta de Quito incluyó a varios altos funcionarios de la Audiencia y Real Hacienda, en su mayor parte de origen peninsular o de otras partes de América, además de otros españoles europeos y criollos. En comparación con los otros integrantes de la capa social alta, la mayor parte de las familias de la nobleza titulada tuvo la ventaja de prolongarse en el espacio y en el tiempo, hecho que les facilitó ejercer constantemente cargos y funciones importantes en varios ámbitos de la sociedad.

La diferenciación entre la nobleza titulada y el resto de la población urbana no fue nítida, puesto que la mayor parte de los titulares procedía de la capa social alta del distrito de la misma Audiencia. Además, no obstante los rasgos comunes de las familias estudiadas, algunas de éstas, como los Maldonado, tuvieron problemas económicos en la época colonial tardía, mientras otras, como los Sánchez de Orellana, llegaron a la cúspide de su historia familiar. Había también algunas familias, como los Villacís, que a pesar de no gozar de un título de Castilla eran muy acaudaladas y fueron reputadas de pertenecer a la primera nobleza de la ciudad. La nobleza titulada no gozó tampoco de privilegios propios. Por esta razón los títulos de Castilla fueron más bien el signo más prestigioso e incuestionable de pertenecer a la nobleza de Quito, término y concepto coetáneo más importante para referirse a la capa social alta de la ciudad.

De la nobleza titulada de Quito solamente el marquesado de Maenza fue concedido en 1625 a un ascendiente español de la familia quiteña de los Matheu, mientras que las otras familias beneficiadas se habían establecido en América ya antes de la concesión del título de Castilla. La mayor parte de los títulos fueron concedidos a partir de la segunda mitad del siglo XVII, cuando la Corona española aumentó la concesión de títulos y de hábitos de las órdenes nobiliarias a sus súbditos americanos. Con la excepción del marquesado de Selva Alegre, otorgado en el Perú en 1747, el resto de los títulos quiteños fue concedido directamente a familias del distrito de la Audiencia: 1692 (Selva Florida), 1700 (Solanda), 1703 (Villa Rocha), 1745 (Lises), 1751 (Miraflores), 1753 (Villa Orellana), 1771 (Real Agrado) y 1784 (Casa Jijón). ${ }^{4}$ Cinco de estos títulos (el condado de Selva Florida y los

4 Guzmán, José Alejandro: Títulos nobiliarios en el Ecuador, Madrid, 1957. En 1815, Manuel de Larrea y Jijón, pariente inmediato de los marqueses de Selva Alegre, recibió otro título, el marquesado de San José. También entre los primeros caballeros de hábito oriundos de la ciudad de Quito, beneficiados igualmente a partir de fines del siglo XVII, figuraron ya ascendientes y miembros de las familias de la nobleza titulada, es decir los Flores, Jijón, Larrea, Maldonado, Matheu y Sánchez de Orellana, véase Lohmann Villena, Guillermo: Los americanos en las órdenes nobiliarias (1529-1900), 2 tomos, Madrid, 1947. 
marquesados de Lises, Miraflores, Solanda y Villa Orellana) fueron concedidos previo pago de una suma cifrada entre 22.000 y 30.000 pesos.

El hecho de que al final de la época colonial toda la nobleza titulada del distrito de la Audiencia viviese en Quito se debe a la calidad de esta ciudad de ser el centro político, económico y social de todo el distrito. ${ }^{5} \mathrm{Al}$ mismo tiempo, Quito era la ciudad más importante de un espacio más reducido, o sea la sierra norte y central, que se extendía del corregimiento de Ibarra en el norte al corregimiento de Ambato en el sur. Las actividades económicas y los empleos de las familias de la nobleza titulada se situaron en todo este espacio, por cuyo motivo algunos de sus miembros se trasladaron de manera temporal o incluso continuada a otras villas y asientos de la región.

Centrándonos en los principales apellidos de la nobleza titulada de la época colonial tardía, se puede decir que, aunque el origen de las respectivas familias era muy variado, una vez establecidas en la sierra norte y central del distrito, su desarrollo y características fueron muy parecidos. ${ }^{6} \mathrm{La}$ inmigración de los fundadores americanos de estas familias comprende un largo período que va desde fines del siglo XVI hasta la primera mitad del XVIII. Mientras que entre los inmigrantes más antiguos sólo hubo unos pocos encomenderos, otros, como los primeros Guerrero, lograron emparentarse rápidamente con descendientes de conquistadores, primeros pobladores o encomenderos de la región.

No todos los primeros miembros de las familias estudiadas llegaron directamente desde España a Quito (los Carcelén y Maenza, siglo XVII), sino que algunos se radicaron primero en otras ciudades de la sierra (los Guerrero, final del siglo XVI; los Flores, Jijón y Maldonado, siglo XVII; los Sánchez de Orellana y Villavicencio, siglo XVIII) o en otras ciudades americanas, por ejemplo del Perú (los Montúfar, siglo XVIII).

En el origen de varios linajes quiteños encontramos a varios corregidores del distrito de la Audiencia, beneficiados con el título antes o poco después de su llegada; por ejemplo, los Jijón, Maldonado y Sánchez de Orellana en el siglo XVIII. Sólo la familia Montúfar tuvo un alto funcionario, nada menos que presidente de la Audiencia, como fundador de su linaje.

5 No se consideran aquí títulos concedidos a vecinos de la gobernación de Popayán, que perteneció en parte al distrito de la Audiencia de Quito.

6 Véase Ortiz de la Tabla, Javier: Los encomenderos de Quito 1534-1660. Origen y evolución de una élite colonial, Sevilla, 1993; Büschges, Christian: Familie, Ehre und Macht. Konzept und soziale Wirklichkeit des Adels in der Stadt Quito (Ecuador) während der späten Kolonialzeit, 1765-1822, Stuttgart, 1996, págs. 142-153. 
Desde un principio, los ascendientes de esta nobleza crearon sus patrimonios sobre la base de obrajes y haciendas, y diversificaron sus ingresos comerciando con productos propios y con ropas y otros efectos europeos adquiridos preferentemente, hasta la primera mitad del siglo XVIII, en Lima. Al mismo tiempo, a partir del siglo XVII, se puede constatar una presencia continua en el cabildo de Quito de las primeras generaciones de algunas de estas familias.

A partir de su llegada a la ciudad todos los miembros de estas familias trataron de confirmar y consolidar su ascenso social, emparentándose con las familias ya establecidas y más importantes del lugar, algunos de cuyos apellidos que databan de la época de la conquista se perdieron a través del tiempo. Desde finales del siglo XVI se puede observar una tendencia endogámica constante entre la capa social alta, por cuya razón en la época colonial tardía pocas familias quiteñas solían, y efectivamente podían, reclamar su descendencia de los conquistadores y primeros pobladores del país. ${ }^{7}$

El discurso del linaje, o sea de la ascendencia y pertenencia a las familias destacadas de la ciudad y del distrito de la Audiencia, sirvió a las familias reconocidas como nobles para defender la distinción y exclusividad social que reclamaban, reflejando de este modo un aspecto típico de las aristocracias de las sociedades jerárquicas de la época moderna. A continuación se analiza más extensamente la base económica y las funciones públicas de la nobleza titulada quiteña durante la época colonial tardía, así como también las relaciones de parentesco y socioeconómicas que existían en su interior y entre las familias respectivas.

\section{El patrimonio}

Desde la fundación de Quito en 1534 el espacio urbano fue un espejo de la estructura de la sociedad, puesto que aparte de los edificios administrativos, las iglesias y los conventos, las casas alrededor de la plaza mayor y de todo el centro de la ciudad pertenecieron a los oficiales reales, al alto clero y a los hacendados y comerciantes más ricos. ${ }^{8}$ Durante la época colo-

7 Para los siglos XVI y XVII véase Ortiz de la Tabla, Javier: "Si quieres casar toma tu par", en Encomiendas, indios y españoles, ed. por Julián B. Ruiz Rivera y Horst Pietschmann, Münster, 1993, págs. 145-181.

8 Véase Achig, Lucas: El proceso urbano de Quito, Quito, 1983. 
nial tardía, toda la nobleza titulada tuvo sus casas de morada en la parroquia central de El Sagrario o en la parte colindante de la parroquia de Santa Bárbara, mientras que las parroquias periféricas albergaron sobre todo a la población blanca empobrecida, mestiza e indígena, o sea a los llamados plebeyos, a pesar de que muchos indígenas y mestizos vivían y trabajaban en el centro en una casa perteneciente a la capa social alta. ${ }^{9}$

Las casas del centro eran comúnmente de una planta, al contrario de los edificios simples de los barrios periféricos. Describiendo las casas del centro quiteño el naturalista bogotano Francisco José de Caldas constató en 1805 que "la nobleza y el estado medio ocupan siempre el alto [piso]; las piezas bajas están destinadas a la plebe" ${ }^{10}$ Muchas casas del centro albergaron, aparte de la familia del dueño, a otros parientes, criados y esclavos, así como viviendas, tiendas y almacenes propios o dados en arriendo; de manera que una casa venía a ser un pequeño pueblo. ${ }^{11}$ En la casa de Mariano Flores y Vergara, segundo marqués de Miraflores, vivían en 1797 veinte personas: el marqués, su esposa, dos hijos adoptados, otra mujer del mismo apellido, nueve esclavos negros y seis criadas indígenas. ${ }^{12}$

El valor de las casas privadas más grandes de la ciudad podía alcanzar unos 15.000 pesos, aunque la mayoría de las mansiones de la nobleza titulada valían entre 5.000 y 8.000 pesos y estaban comúnmente gravadas con censos. En cambio, el valor de las casas de los barrios periféricos solía ser de unos cientos de pesos. A pesar de que, en comparación con los palacios urbanos de las capitales virreinales de México o Lima, las casas quiteñas eran más bien modestas, algunas familias nobles de Quito vivieron en edificios grandes, equipados de mobiliario y decoración de lujo. La casa del mayorazgo de los condes de Selva Florida, situada en un lado de la plaza del monasterio de San Francisco, era sin duda el edificio privado más imponente de la ciudad y abarcaba, con su jardín, una manzana entera. El primer edificio de esta casa había sido adquirido por el primer ante-

9 Véase Jurado Noboa, Fernando: Plazas y plazuelas de Quito, Quito, 1989; del mismo autor: Calles de Quito, Quito, 1989; Lucena Salmoral, Manuel: "La ciudad de Quito hacia mil ochocientos", Anuario de Estudios Americanos, LI:1, Sevilla, 1994, págs. 143-164.

10 Caldas, Francisco José de: "Viaje de Quito a Popayán", en La economía colonial. Relaciones socio-económicas de la Real Audiencia de Quito, ed. por Manuel Miño Grijalva, Quito, 1984, pág. 238; véase el juicio coetáneo parecido de Stevenson, William B.: "Cómo era Quito cuando se declaró libre", en El Ecuador visto por los extranjeros (Viajeros de los siglos XVIII y XIX), ed. por Humberto Toscano, Puebla, 1959, pág. 222.

11 Caldas: "Viaje de Quito...", pág. 238.

12 "Padrón del cumplimiento de la iglesia de Santa Bárbara". Año de 1797, Archivo de la Curia, Quito (en adelante, AC/Q), Gobierno del obispo Calama. 
pasado quiteño de los condes, Pedro Ponce de León, en $1595 .{ }^{13}$ Aparte de las casas principales de morada, las familias más acaudaladas disponían de otras casas que formaban parte de un mercado inmobiliario relativamente vivo. ${ }^{14}$

Además de representar el prestigio y patrimonio de una familia y su linaje, algunas casas particulares sirvieron como centros de las relaciones sociales de la capa social alta, sobre todo con ocasión de fiestas privadas o públicas, o para hospedar a viajeros famosos como Alejandro de Humboldt o al ya mencionado Francisco José de Caldas. ${ }^{15}$

Mientras que las casas urbanas de las familias quiteñas analizadas cumplieron en primer lugar un papel social, las fincas rurales tuvieron sobre todo una función económica. La prosperidad de la nobleza titulada de Quito se basó en gran medida en sus haciendas, ubicadas en los corregimientos de Ibarra, Otavalo, Quito, Latacunga, Ambato y Riobamba. ${ }^{16} \mathrm{De}$ los bienes rurales, desde las pequeñas estancias hasta las grandes haciendas, salió una amplia gama de productos agropecuarios, con algunas especializaciones locales (como la caña o los productos lácteos), que fueron consumidos en las mismas fincas o vendidos en los mercados urbanos del corregimiento respectivo o en otras ciudades de la región. Una porción importante de los ingresos de la economía rural se originó, hasta el final del régimen colonial, en los grandes obrajes que fueron una parte esencial del sistema hacendario. ${ }^{17}$

Como en la mayor parte de la América hispánica, la producción agropecuaria de la época colonial tuvo generalmente una rentabilidad más bien baja. Además, durante el siglo XVIII decrecieron considerablemente los ingresos de la producción obrajera por la competencia de la industria

13 Jurado Noboa: Plazas y plazuelas..., pág. 99.

14 Los datos sobre los bienes inmobiliarios y las actividades económicas de la nobleza titulada (y de la capa social alta en general) se basan sobre todo en el análisis de 76 (205) testamentos y otros documentos pertenecientes a los registros notariales del Archivo Nacional del Ecuador, Quito (en adelante, ANE/Q).

15 Véase la fiesta pública en la casa del alférez real Mariano Donoso con motivo de la coronación del rey Carlos IV en 1789: "Relación de las Fiestas Reales (...)", Archivo Municipal de Historia, Quito (en adelante, AMH/Q), n. ${ }^{\circ}$ 134, Actas del Consejo, 2 de marzo de 1790, fols. 152-162.

16 De éstas y todas las haciendas comprendidas en 205 testamentos depositados en las notarías quiteñas durante la época colonial tardía, ninguna se ubicó fuera de la región de la sierra norte y central del distrito de la Audiencia.

17 Sobre la industria textil del siglo XVIII véase sobre todo Tyrer, Robson B.: Historia demográfica y económica de la Audiencia de Quito. Población indígena e industria textil, 1600-1800, Quito, 1988. Sobre la producción agropecuaria no existen todavía estudios específicos respecto a la época colonial. 
doméstica y de las importaciones europeas. ${ }^{18} \mathrm{El}$ valor de las haciendas particulares de la capa social alta de la ciudad se cifraba entre unos cientos y 150.000 pesos; el valor de la mayoría de los fundos no pasó sin embargo de los 30.000 pesos. Al igual que las casas urbanas, la mayor parte de las fincas rurales estaba gravada con censos que, dada la escasez de dinero circulante en la región, ofrecieron una fuente de capital importante para facilitar nuevas inversiones. Muchos censos sirvieron además como base de capellanías, obras pías o alimentos, cuyos beneficiarios pertenecían muchas veces a la misma familia y a su parentela.

La mayoría de los hacendados más importantes de la región pertenecía a las familias de la nobleza titulada, de las cuales los Sánchez de Orellana y los Matheu eran los más acaudalados. Jacinto y Joaquín Sánchez de Orellana, herederos únicos del primer marqués de Villa Orellana, obtuvieron en 1787 cada uno, de parte de los bienes del mayorazgo y de las casas urbanas de la familia y descontados todos los censos e hipotecas, varios obrajes y haciendas con un valor de 75.000 pesos, suma considerable para la región en esta época. En cambio, había otras casas nobiliarias, como los Maldonado, que fueron menos afortunadas y solamente poseían unos pocos fundos cargados de fuertes deudas. Al final de la época colonial, además de la nobleza titulada, había también otros terratenientes destacados, como las familias criollas de los Freire y Villacís o individuos como Gabriel Álvarez del Corro y Andrés Fernández Salvador, ambos inmigrantes de la metrópoli.

No obstante su función primordial de proveer a las familias principales de una base económica sólida y estable, algunas fincas rurales, particularmente en el hinterland de la ciudad de Quito, eran a la vez grandes mansiones rurales que, equipadas con una casa de morada, una capilla, muebles lujosos, tejidos y cuadros valiosos, servían como lugares para demostrar el status social de sus dueños. A lo largo del Camino Real, que pasaba por la sierra norte y central del distrito de la Audiencia, varias haciendas ofrecían a los viajeros prominentes, como Caldas o Humboldt, un alojamiento espléndido y una hospitalidad generosa, mientras que los hacendados podían rodearse del lustre de sus huéspedes. William B. Stevenson, secretario del conde Ruiz de Castilla, presidente de la Audiencia de principios del siglo XIX, escribió sobre su llegada a la región en 1806:

18 Büschges, Christian: "Crisis y reestructuración. La industria textil de la Real Audiencia de Quito al final del período colonial”, Anuario de Estudios Americanos, LII:2, Sevilla, 1995, págs. 75-98. 


\section{CHRISTIAN BÜSCHGES}

"Partimos a la mañana siguiente de nuestra llegada a [La] Tacunga, y avanzamos hasta la hacienda Chisinchi [del marqués de Villa Rocha], y al otro día a la [Hacienda de la] Ensillada, de propiedad del Marqués de Villa Orellana, en donde se congregaron todas las autoridades y personalidades de Quito, con el objeto de cumplimentar a su Presidente y Capitán General". ${ }^{19}$

Los latifundios eran pues un fundamento esencial de la prosperidad y del prestigio de una persona y de su familia. A pesar de que hubo un mercado vivo de bienes rurales, ${ }^{20}$ existían haciendas famosas firmemente ligadas a los patrimonios de algunas de las familias de la nobleza titulada de Quito, perpetuando la prosperidad y el apellido de sus linajes.

Sin embargo, como el derecho sucesorio español proveía la partición equitativa de la herencia entre todos los hijos, la continuidad del patrimonio se veía amenazada por la dispersión de los bienes familiares entre muchos herederos. Sólo las grandes familias, poseedoras de un patrimonio extenso, lograron sin problemas mantener la integridad de sus bienes más productivos y prestigiosos, como se ve en el caso de Manuel de Jijón y León. Según sus testamentos de 1799 y 1801, Manuel dejó seis hijos con derecho a la sucesión de sus bienes. Se debió sólo al hecho de que Manuel había heredado antes las propiedades de su hermano Miguel, primer conde de Casa Jijón y muerto sin sucesión, que todos sus hijos heredaron varias haciendas de un patrimonio que comprendía, en el momento de su división, 15 haciendas, potreros y hatos. ${ }^{21}$

Para evitar la dispersión de los patrimonios algunas familias quiteñas habían optado, a partir de la primera mitad del siglo XVII, por fundar un mayorazgo, institución de origen peninsular que permitió legar una parte fija del patrimonio a los hijos primogénitos de un linaje. ${ }^{22}$ La función socioeconómica del mayorazgo se desprende, por ejemplo, de una licencia que el rey Felipe V dio en 1712 a los fundadores del mayorazgo de los marqueses de Maenza:

"En la división de los bienes resultan grandes inconvenientes, y por ellos se pierden

y se destruyen las familias y memorias de las personas nobles e ilustres, y por con-

19 Stevenson: "Viaje de Guayaquil...", pág. 218. Otra hacienda famosa por su función de centro social fue la hacienda de Chillos de Juan Pío Montúfar y Larrea, segundo marqués de Selva Alegre, situada al sur de la ciudad de Quito.

20 Véase Fernández Martínez, Montserrat: La alcabala en la Audiencia de Quito, 1765-1810, Sevilla, 1984.

21 Testamentos de Manuel de Jijón, Archivo Histórico del Banco Central, Quito (en adelante, AHBC/Q), Documentos particulares, núms. 660 y 664.

22 Acerca del origen y de la estructura general de la institución véase Clavero, Bartolomé: Mayorazgo. Propiedad feudal en Castilla, 1369-1836, Madrid, 1974. 
trario se conservan y perpetuan, quedando enteras y unidas por medio de la institución de los mayorazgos". ${ }^{23}$

Al final del siglo XVIII existían en el distrito de la Audiencia de Quito diecisiete vínculos y mayorazgos. ${ }^{24}$ De estos vínculos, trece se ubicaban en la sierra norte y central, y de ellos diez pertenecían a familias quiteñas. Estos diez vínculos comprendían además los seis mayorazgos más valiosos de todo el distrito de la Audiencia, cuyo valor variaba entre alrededor de 20.000 y 140.000 pesos. Dichos mayorazgos pertenecían a los marqueses de Selva Florida (fundado en 1638), Maenza (1705), Solanda (1735) y Villa Orellana (1782), y a las familias Freire (segunda mitad del siglo XVII) y Villacís (1679). Los marqueses de Maenza y una rama de la familia Sánchez de Orellana disfrutaron además de las rentas de un mayorazgo en la metrópoli. ${ }^{25}$

A pesar de que para un mayorazgo se podía vincular en principio cualquier bien o renta, los grandes mayorazgos quiteños se componían siempre de una casa urbana y de unas haciendas, que comprendían en la mayoría de los casos un obraje, reflejando de esta manera la estructura típica de los latifundios de la región. ${ }^{26}$

Cabe señalar que las familias de los marqueses de Maenza y de los condes de Selva Florida tenían, al final del siglo XVIII, problemas para mantener los bienes y el capital fijados en las respectivas actas de fundación de sus mayorazgos, hecho aparentemente debido tanto a faltas individuales como a las consecuencias económicas de la crisis de los obrajes. No obstante, los mayorazgos no perdieron su aprecio general en la alta sociedad quiteña. ${ }^{27}$

23 "Autos de don Manuel Mateu, sobre ser el sucesor en el mayorasgo que mandó fundar Don Mateo de la Escalera (...)", ANE/Q, Testamentarías, exp. 4-IV-1778, fol. 34.

24 Esta cifra se basa en los fondos Vínculos y Mayorazgos, Testamentarías y Notarías (Protocolos) del ANE/Q; véase Valencia Sala, Gladys: El mayorazgo en la Audiencia de Quito, Quito, 1994. No existía, por lo menos para el caso del distrito de la Audiencia de Quito, una clara distinción de derecho o de hecho entre un vínculo y un mayorazgo. El término vínculo fue utilizado comúnmente en el distrito en un sentido genérico (incluyendo dos obras pías) y además para denominar los bienes vinculados más pequeños. La cifra total de mayorazgos no incluye vínculos fundados en la parte de la gobernación de Popayán que pertenecía a la jurisdicción de la Audiencia de Quito.

25 Las rentas anuales fueron de 4.000 y 300 pesos, respectivamente (ANE/Q, Testamentarías, exp. 16-I-1794; Matrimoniales, exp. 27-XI-1798).

26 Faltó a los mayorazgos quiteños, e hispanoamericanos en general, el carácter feudal de los mayorazgos castellanos, cuyas rentas se originaron de los impuestos pagados por los vasallos que habitaban las tierras del vínculo; ver Clavero: Mayorazgo..., págs. 102-103 y 181-205.

27 En 1786 la segunda marquesa de Miraflores, Margarita Ignacia de Bobadilla, legó en su testamento a su marido la fundación de otro mayorazgo, "que conserve el lustre de la familia y el esplendor de dicho título de Castilla, para que de esta manera no se disminuyan ni separen aquellas fincas, sobre cuyo valor puede hacerse dicha fundación”, ANE/Q, 1. Notaría (Protocolos), t. 425, exp. 13-V-1786, fol. 433v. La fundación no se llevó a cabo. 
Junto a la producción agropecuaria y textil las actividades económicas de la nobleza titulada incluyeron el comercio, tanto con la propia producción como con otros productos domésticos o importados, y la minería. El comercio textil se dirigió sobre todo hacia la gobernación de Popayán, que adquirió una importancia cada vez más grande durante la segunda mitad del siglo XVIII, a causa del aumento de la producción aurífera en las minas de la costa pacífica. Hubo, sin embargo, pocos comerciantes puros en las filas de las familias de la nobleza titulada que invirtiesen de manera constante e independiente de la producción propia en el comercio activo. La mayoría de este comercio se desarrolló a nivel interregional, o sea entre Quito y Lima o, sobre todo, Cartagena.

Casi ningún comerciante de la nobleza titulada y del comercio quiteño en general se dedicó al gran comercio con la metrópoli. Una excepción era la empresa familiar del tercer marqués de Solanda, Fernando Sánchez de Orellana, y otros familiares y parientes en Quito y Madrid que se dedicaban, alrededor de mediados del siglo XVIII, al comercio de textiles europeos entre Quito y la península, a través de Cádiz y Cartagena, donde tenían factores propios. Sin embargo, después de la muerte del familiar madrileño, la empresa fue liquidada a partir de 1767.28

Entre los representantes más importantes del comercio quiteño con Popayán y Cartagena, dentro de la nobleza titulada, figuraron en primer lugar Pedro Montúfar y Larrea, hermano del segundo marqués de Selva Alegre; el abogado Mariano Maldonado y Borja, hijo del segundo marqués de Lises, y el primer marqués de Villa Orellana, Clemente Sánchez de Orellana. Además, a la parentela de las familias principales perteneció, durante la época colonial tardía, un comerciante peninsular, Pedro Buendía y Dávila, que se dedicaba igualmente al comercio interregional. Por otra parte, algunos miembros de las familias principales, comenzando por Pedro Montúfar, ejercieron el cargo de juez de comercio que, a falta de un gremio, vigilaba la vida comercial de la ciudad de Quito.

Durante el siglo XVIII la minería tuvo solamente una importancia marginal para la estructura económica de la sierra norte y central del distrito de la Audiencia. Escaseaban no solamente vetas prometedoras y accesibles sino también conocimientos específicos y capital. ${ }^{29}$ Por esta

28 Ibídem, t. 388, fols. 291-295; Testamentarías, exp. 28-VI-1791.

29 Véase Darquea, Bernardo de: "Brief an und für den Vizekönig von Neu-Granada, J. de Ezpeleta", 3 de noviembre de 1789, Handschriftenabteilung, Nachlaß Alexander von Humboldts, Kleiner Kasten 7b, núm. 38, fols. 1-4v., Stiftung Preussischer Kulturbesitz, Berlín. 
razón hubo pocos vecinos quiteños que arriesgaran sus caudales en la explotación de algunas minas de plata. Entre estos mineros se puede destacar a Manuel Guerrero y Ponce de León, heredero del condado de Selva Florida, que mantenía al final del siglo XVIII, en compañía del comerciante quiteño Miguel Ponce y sin rendimiento alguno, dos de estas minas verdaderas o supuestas, pertenecientes al terreno de una de sus haciendas en el corregimiento de Latacunga. ${ }^{30} \mathrm{El}$ único minero verdadero y exitoso entre la capa social alta de la ciudad fue Pedro Quiñones y Cienfuegos, miembro de una antigua familia minera de Barbacoas, en la gobernación de Popayán, que se casó en Quito con la tercera marquesa de Miraflores al final del siglo XVIII. ${ }^{31}$

\section{Empleos, rangos y profesiones}

Quito albergó las más importantes instituciones de la administración civil, eclesiástica y militar del distrito de la Audiencia. Miembros de las familias de la nobleza titulada de la ciudad ocuparon una gran parte de los empleos y funciones en estos ámbitos, en cuanto la política real, los reglamentos de las instituciones y la capacidad e influencia personales y familiares lo permitían. Además, entre los criollos de la capa social alta de Quito fueron solamente los miembros de la nobleza titulada y su parentela inmediata quienes dirigieron sus peticiones de un empleo importante directamente a la Cámara de Indias, destacando sobre todo el status social y los méritos de sus ascendientes. ${ }^{32}$ Como en el caso de los bienes raíces, los empleos y funciones que los miembros de estas familias ejercieron se ubicaron no sólo en la capital de la Audiencia y sus términos, sino también en otros corregimientos de la región, pero muy raras veces fuera de ésta. ${ }^{33}$

30 Testamento de Manuel Guerrero, ANE/Q, 1. Notaría (Protocolos), t. 444, exp. 4-IX-1799, fol. 310v; Testamentarías, exp. 2-IX-1799; 6. Notaría (Juicios), exp. 18-XI-1802.

31 Testamento de su hijo Mauricio, ANE/Q, 1. Notaría (Protocolos), t. 474, exp. 19-VI-1815; AMH/Q, núm. 6, Cartas y Comunicaciones privadas. Siglo XIX; véase Jurado Noboa, Fernando: Esclavitud en la costa pacífica. Iscuandé, Tumaco, Barbacoas y Esmeraldas. Siglos XVI al XIX, Quito 1990, págs. 292 y 324.

32 Véanse las relaciones de méritos en Archivo General de Indias (AGI), Audiencia de Quito, legs. 195 y 224-230.

33 Partiendo de una reconstrucción de las familias de la nobleza titulada y su parentesco inmediato, 130 personas han podido ser registradas según los empleos y funciones que ejercieron en las diferentes esferas de la sociedad durante la época colonial tardía. 
El provecho que sacó el titular de un empleo en la administración, la iglesia o la milicia incluía en el caso de los cargos más importantes, junto al influjo directo en un campo particular de la vida social, un alto prestigio, pues solamente los empleos civiles y eclesiásticos más altos estaban dotados de una remuneración suficiente para sostener un estilo de vida dispendioso y representativo. De todas maneras los empleos de mayor rango proporcionaban a sus titulares una base económica suficiente y constante. En la administración real los cargos mejor dotados eran los de presidente y oidores de la Audiencia que ganaban, al final del siglo XVIII, 6.000 y 3.300 pesos por año, respectivamente. Los corregidores recibían algo más de 1.000 pesos. Los ingresos de los funcionarios de la Real Hacienda pocos pasaban de los 1.000 pesos o consistían, en el caso de algunos escribanos y secretarios, exclusivamente en los impuestos y derechos cobrados en el ejercicio de su función. ${ }^{34}$

La Audiencia, como institución administrativa más importante del distrito, comprendió los cargos más altos y mejor dotados de la región estudiada. Sin embargo, las familias de la nobleza titulada y en general los criollos quiteños ejercieron pocos empleos de esta institución, puesto que los reyes borbónicos preferían conceder estos cargos a peninsulares y criollos nacidos en otras regiones del espacio colonial. ${ }^{35}$ Además, las exigencias respecto a la cualificación de los candidatos eran particularmente altas en el caso de los cargos más importantes de la Audiencia, razón por la cual a un miembro de la familia Sánchez de Orellana le fue negado, en la primera mitad del siglo XVIII, la concesión del cargo de oidor. ${ }^{36}$

Una excepción fue la concesión de la presidencia de la Audiencia a Fernando Sánchez de Orellana, tercer marqués de Solanda, en 1744; por ser oriundo del mismo distrito debió pagar 27.000 pesos por el empleo, que ejerció de 1745 a $1754 .{ }^{37}$ Además, dados los a veces largos intervalos entre la muerte o el relevo de un funcionario y la llegada de su sucesor, o

34 "Relación exacta y circunstanciada de todos los empleos políticos de Real Hacienda, y Militares que hay en la ciudad de Quito y toda su Provincia (...)" [1786], primera parte, Boletín del Archivo Nacional de Historia, IV:6, Quito, 1956, págs. 89-99.

35 Véase Burkholder, Mark A. y Dewitt S. Chandler: From impotence to authority. The Spanish crown and the American Audiencias, 1687-1808, Columbia y Londres, 1977.

36 Herzog, Tamar: "¿Letrado o teólogo? Sobre el oficio de Justicia de Quito a principios del siglo XVIII", Fallstudien zur spanischen und portugiesischen Justiz, 15. bis 20. Jahrhundert, ed. por Johannes-Michael Scholz, Francoforte sul Meno, 1994, págs. 697-714.

37 Herzog, Tamar: "La empresa administrativa y el capital social: los Sánchez de Orellana (Quito, siglo XVIII)", ponencia presentada en el simposio del grupo Personal Administrativo y Político Español (Centre National de Recherches Scientifiques, París), Granada, 1994. 
también en épocas de mucho trabajo, la Audiencia nombró de vez en cuando conjueces o fiscales interinos, entre los cuales figuraron algunos familiares de la nobleza titulada, como el ya mencionado Pedro Quiñones y Cienfuegos.

Más amplia fue la presencia de las familias estudiadas y de los criollos en general en la jerarquía mediana de la administración real, o sea en el caso de los funcionarios de la Real Hacienda y de los corregidores, aunque al final de la época colonial bajó el número de criollos beneficiados con corregimientos. Cumpliendo de nuevo un paradigma ya bien conocido, después de establecerse en la ciudad de Quito, los miembros de las familias estudiadas no ejercieron generalmente ningún empleo de Real Hacienda o de corregidor fuera de la sierra norte y central. Los corregidores eran elegidos por el rey de una lista de candidatos elaborada por la Cámara de Indias. La mayor parte de los cargos de la Real Hacienda fue rematada por la misma Audiencia, a pesar de que el rey concedió a veces un cargo directamente.

El verdadero dominio de las familias principales de Quito fue el nivel más bajo de la administración civil, o sea el cabildo, en el cual ingresaron miembros de todas las familias estudiadas, con excepción de los Villavicencio, cuyos familiares ocuparon en cambio cargos del ayuntamiento de la villa de Riobamba.

Tanto en el caso de las regidurías como en el de los empleos municipales los criollos fueron una mayoría abrumadora, incluso respecto a las dos alcaldías ordinarias quiteñas, puesto que la ley de la alternativa entre candidatos criollos y peninsulares no fue estrictamente observada, debido en parte al reducido número de vecinos peninsulares en la ciudad. ${ }^{38}$ Las regidurías perpetuas fueron rematadas por la Audiencia. Sin embargo, los regidores tenían la posibilidad de renunciar a su cargo en favor de otra persona, que en la mayoría de los casos fue un pariente inmediato. Los titulares de los empleos municipales eran elegidos a principios de cada año por el mismo cabildo.

El ejercicio de la mayor parte de las regidurías y empleos fue a título honorífico, sin ninguna remuneración, y el deseo de obtenerlos estuvo ante todo motivado por el prestigio que daban a sus titulares y no tanto por ra-

38 Según un cálculo del año 1765 vivían 51 vecinos y 23 moradores peninsulares en la ciudad; véase "Relación sumaria de las dos sublevaciones de la plebe de Quito", Boletín de la Academia Nacional de la Historia, XV: 42-45, Quito, 1937, págs. 102-116. 
zones económicas. ${ }^{39}$ Además para la adquisición de algunas regidurías y cargos municipales fue necesario una inversión de algunos cientos o miles de pesos..$^{40}$

La autoridad y la influencia concreta de los titulares de los diferentes empleos y funciones sobre la sociedad, como también la posición de los individuos y grupos sociales frente a las instituciones de administración, son temas muy complejos que, por falta de espacio, no se pueden tratar aquí. ${ }^{41}$ Cabe mencionar que el cabildo, órgano político más importante para la representación de los intereses de la capa alta de la sociedad local, controlaba algunos aspectos importantes de la vida económica de la ciudad y su hinterland, por ejemplo, a través de la concesión de créditos a censo, los arrendamientos de tierras de los ejidos o la organización del abasto de la carnicería municipal. Estas facultades del cabildo favorecieron a varios familiares de la nobleza titulada, sin que fuese necesario que los beneficiados respectivos hubiesen sido miembros del cabildo.

El acceso de las familias estudiadas, y de los criollos locales en general, a los cargos de la jerarquía eclesiástica fue similar a la situación en la administración civil. En el cabildo eclesiástico, institución más importante, la presencia de los criollos fue bastante restringida. La excepción más notable fue otra vez Fernando Sánchez de Orellana a quien, después de haber servido la presidencia de la Audiencia, el rey nombró deán de la catedral, con un sueldo anual de 2.500 pesos. ${ }^{42}$ La mayoría de los eclesiásticos de las familias de la nobleza titulada eran curas o clérigos presbíteros que, por falta de un curato propio, servían capellanías que en muchos casos pertenecían a la misma familia. El capellán más notable fue, sin embargo, el cura de Cayambe (corregimiento de Otavalo), Domingo de Larrea y Villavicencio, quien sirvió a lo largo de su vida nada menos que 23 capellanías

39 Sólo algunos cargos subalternos, que no fueron normalmente ejercidos por miembros de la capa alta social, recibieron una indemnización de poco más de 100 pesos anuales por los gastos ligados al empleo, véase "Cuentas generales (...) de la renta de propios del Cabildo de Quito, de los años de 1788 a 1796 (...)”, ANE/Q, Fondo Especial. Presidencia de Quito, c. 158, documento 8603-5, exp. 10-X-1799, fols. 46-49v.

40 A José Román y Sánchez de Orellana le costó una regiduría sencilla en 1787 la suma de 250 pesos, ANE/Q, 6. Notaría (Protocolos), t. 99, exp. 14-IX-1787, fols. 198-199. Juan José Guerrero y Matheu pagó en 1801 por el empleo de regidor-fiel ejecutor 4.000 pesos, ibídem, t. 114, exp. 10-I-1801, fols. $69-70 \mathrm{v}$.

41 Véase Herzog, Tamar: La administración como un fenómeno social. La justicia penal de la ciudad de Quito (1650-1750), Madrid, 1995.

42 ANE/Q, 1. Notaría (Protocolos), t. 392, exp. 1-X-1765, fols. 188v-192v.; AGI, Audiencia de Quito, 195 в y 579. 
cuyos censos valían entre 200 y 6.000 pesos..$^{43} \mathrm{~A}$ causa de sus ingresos relativamente bajos e inestables algunos presbíteros y también curas tenían para su sustento haciendas propias.

Los curatos servidos por los familiares de la alta nobleza quiteña se ubicaron no solamente en la ciudad de Quito, sino en toda la región de la sierra norte y central. Algunos clérigos comenzaron su carrera eclesiástica como curas de pueblos ajenos a la capital para obtener después un curato quiteño. El doctor Gregorio de León y Mendoza, pariente de los condes del Real Agrado y de los marqueses de Villa Rocha, logró de esta manera subir, tras su formación en el Colegio Real de San Fernando, de cura interino del pueblo de Calpi, cerca de Riobamba, a maestre escuela de la catedral de Quito, beneficio que le proporcionó un sueldo anual de 2.000 pesos ${ }^{44} \mathrm{Al}$ contrario que en la administración civil, una carrera de este tipo en el distrito de la Audiencia no fue excepcional en la jerarquía eclesiástica, donde el criterio del origen social de los candidatos tuvo obviamente un peso menor frente a la cualificación y formación personal.

Finalmente, se encuentran solamente dos frailes en las filas de las familias estudiadas, ambos ejerciendo funciones importantes de su orden respectiva. El número de monjas fue considerablemente más alto, 18 en total, sin poder hacer suponer que hubiera existido una política decisiva de parte de estas familias de reducir por este procedimiento el número de herederos.

Junto con los cargos civiles y eclesiásticos, los rangos militares tuvieron siempre un gran prestigio en el distrito de la Audiencia. Sin embargo, antes de la creación sistemática de cuerpos de milicias, entre 1779 y 1784, la organización militar de la región no ofreció una cantidad considerable de cargos y rangos. Al contrario de la reforma del sistema de milicias en la Nueva Granada, los rangos del distrito de la Audiencia de Quito, incluso los más altos, fueron dados preferentemente a los criollos. ${ }^{45}$ Por esta razón encontramos entre los oficiales de los diferentes cuerpos miembros de todas las familias estudiadas. Además, el sistema de milicias fue quizás el sector público en el cual el predominio social de la alta nobleza quiteña fue más visible, puesto que los rangos principales de coronel y teniente coronel y las plazas de las planas mayores voluntarias de los regi-

43 Véase su testamento, ANE/Q, 6. Notaría (Protocolos), t. 119, exp. 21-XI-1803, fols. 115v-124v.

44 Véase "Relación de los méritos, grados y literatura del Doctor D. Gregorio de León y Mendoza (...)" [1754], AGI, Audiencia de Quito, 195 A.

45 ANE/Q, Milicias; Relación exacta..., págs. 84-89 y 103-105; véase Kuethe, Allan J.: Military reform and society in New Granada, 1773-1808, Gainesville, 1978. 
mientos fueron dominados por algunos títulos de Castilla y sus familiares más cercanos.

También los rangos y cargos militares concedidos a la capa social alta de Quito comprendieron toda la sierra norte y central, a excepción del rango de coronel de infantería de un batallón de la ciudad de Cuenca, en la sierra sur, que fue concedido a Pedro Buendía y Dávila, yerno del tercer marqués de Villa Rocha. Todos estos rangos de las milicias fueron empleos honoríficos, sin sueldo, pero con mucho prestigio vinculado a los uniformes de gala y al fuero militar.

Resta mencionar la gran cantidad de abogados que se reclutaron de casi todas las familias de la nobleza titulada, aunque eran la excepción los que vivían solamente de los ingresos de esta profesión. Otros empleos para cuyo ejercicio era necesario una preparación formal fueron los cargos universitarios, pertenecientes hasta la época colonial tardía a los colegios mayores de los jesuitas, los dominicos y los agustinos, hasta que en 1776 el rey Carlos III ordenó la fundación de la universidad de Santo Tomás. ${ }^{46}$ A partir de aquel año aumentó el acceso de las familias estudiadas a los cargos universitarios. Hasta el final de la época colonial varios miembros de estas familias ocuparon una cátedra de leyes o de alguna otra materia.

\section{Parentesco y redes familiares}

Las relaciones familiares y de parentesco entre la nobleza titulada de Quito con otras familias ilustres de la ciudad tuvieron una importancia central para conservar y fortalecer la destacada posición social tanto de las personas y familias particulares como de todo el núcleo de la capa social alta. Siguiendo el modelo que caracterizó a la nobleza española y europea desde la transición del Medioevo a la época moderna, las familias con títulos de Castilla de Quito cumplían en gran escala el principio aristocrático del matrimonio justo, o sea correspondiente al propio status social. ${ }^{47}$

46 Lucena Salmoral, Manuel: "Entre la escolástica y el despotismo ilustrado. Reformismo universitario en Quito en vísperas de la Independencia”, en La universidad ante el Quinto Centenario, actas del Congreso Internacional de Universidades (Madrid, 13-16 julio 1992), Madrid, 1993, págs. 193-207; ídem: "Una universidad que nunca tuvo estatutos: Santo Tomás de Quito", Estudios de Historia Social y Económica de América, IX, Alcalá de Henares, 1992, págs. 99-115.

47 Para el caso de la metrópoli véase por ejemplo Beceiro Pita, Isabel y Ricardo Córdoba de la Llave: Parentesco, poder y mentalidad. La nobleza castellana, siglos XII-XV, Madrid, 1990; Gerbet, Marie-Claude: La noblesse dans le royaume de Castille. Étude sur les structures sociales en Estrémadure (1454 à 1516), París, 1979, págs. 159-192; para la ciudad de Quito durante los siglos XVI y XVII véase Ortiz de la Tabla: "Si quieres casar...". 
Como sus homólogos españoles, la nobleza titulada quiteña buscó fortalecer su pretendida distinción y exclusividad sociales a través de lazos matrimoniales que condujeron a una clara tendencia endogámica dentro de su grupo ${ }^{48}$ Estas familias, antiguas y nuevas, formaron a través de los lazos matrimoniales redes sociales que incluían además a otras familias nobles sin título, como los ya mencionados Villacís y Freire. Las familias Montúfar y Sánchez de Orellana fueron especialmente exitosas, puesto que se vincularon con casi todas las familias importantes de la ciudad. Una consecuencia de esta endogamia fue el hecho de que Felipe Carcelén y Sánchez de Orellana, quinto marqués de Villa Rocha, sucedió en 1803, por los derechos de su madre, también en el marquesado de Solanda.

Las nuevas leyes matrimoniales que los reyes Carlos III y Carlos IV proclamaron a partir de 1776 coadyuvaron, sin duda, a forzar la disciplina familiar, puesto que exigían a los títulos de Castilla pedir una licencia real antes de casarse y aumentaban generalmente el control de los padres de origen español sobre la elección de los cónyuges de parte de sus hijos menores. ${ }^{49}$ Cuando Jacinto Sánchez de Orellana y Chiriboga, hijo primogénito del primer marqués de Villa Orellana, emprendió en 1781 un viaje a España, sus padres le expidieron una licencia para poder casarse con una persona de igual sangre, declarándole al mismo tiempo desheredado para el caso de que fuera a contraer un matrimonio desigual y contra el agrado de sus padres..$^{50}$ Cuando, algunos años después, Josefa Sánchez de Orellana, otra hija de los marqueses, se casó contra la voluntad de éstos, fue efectivamente desheredada. ${ }^{51}$ Puesto que hubo entre las familias de la nobleza titulada pocos casos de pleitos matrimoniales, es evidente que el control informal de los enlaces fue normalmente suficiente. ${ }^{52}$

La tendencia endogámica fue también facilitada por la dispensa matrimonial, mediante la cual el Papa o un vicario suyo podía suspender, en casos particulares, la prohibición eclesiástica de matrimonios entre parientes inmediatos hasta el cuarto grado de consanguinidad, grado correspondiente al número de generaciones que había entre los cónyuges respectivos y su

48 Véanse los cuadros genealógicos en el apéndice I de Büschges: Familie, Ehre und Macht..., págs. 247-262.

49 Véase Rípodas Ardanaz, Daisy: El matrimonio en Indias. Realidad social y regulación jurídica, Buenos Aires, 1977.

50 ANE/Q, 4. Notaría (Protocolos), t. 118, exp. 14-IX-1781, fols. 71-72v.

51 Testamento de la marquesa Javiera Antonia Chiriboga, ANE/Q, 4. Notaría (Protocolos), t. 118, exp. 4-VI-1782, fol. 157.

52 Estos pleitos se encuentran en ANE/Q, Matrimoniales. 
ascendiente común más cercano. Cuando en 1803 el abogado quiteño José Javier Ascásubi y Matheu, nieto del séptimo marqués de Maenza, pidió una dispensa del arzobispo para casarse con su prima Mariana de Matheu y Herrera, justificó su solicitud haciendo hincapié en la dificultad con la que en esta ciudad las personas ilustres podían encontrar sujetos de igual naturaleza para contraer estas alianzas. ${ }^{53}$ Entre las familias de la alta nobleza se efectuaron durante la época colonial tardía tres matrimonios de un segundo grado de consanguinidad, dos de un tercero y dos de un cuarto.

A pesar de los matrimonios endogámicos de la nobleza titulada, ésta se enlazó también con otros criollos considerados como nobles, por ejemplo con miembros de la familia Borja; sin embargo, lo hizo con muy pocos peninsulares. La mayor parte de los matrimonios con criollos se limitó a familias de la misma región de la sierra norte y central, como los Chiriboga, León y Villavicencio, que mantuvieron una fuerte presencia en Riobamba. La familia Sánchez de Orellana fue uno de los pocos ejemplos de una integración exitosa de personas llegadas de la sierra sur; otro caso fue el del comerciante Nicolás de Carrión y Vaca, cuyos hijos se emparentaron a partir de mediados del siglo XVIII con las familias Flores, Jijón, Larrea y Sánchez de Orellana. No existían, en cambio, relaciones de parentesco con familias de la costa.

El hecho de que las relaciones comerciales entre Quito y la gobernación de Popayán aumentaran considerablemente, durante la segunda mitad del siglo XVIII, se refleja también en una inmigración de comerciantes y empresarios del norte hacia esta ciudad. De esta inmigración se originaron algunos enlaces matrimoniales con la alta nobleza quiteña; por ejemplo, parte de los familiares de los Cabezas y los Quiñones. Mientras miembros de la familia Cabezas se vincularon a los Sánchez de Orellana, los Quiñones se emparentaron con los Flores hasta heredar incluso el título de marqués de Miraflores.

Enlaces con familias criollas, radicadas fuera del distrito de la Audiencia, eran más bien escasos y de una importancia menor para la estructura social local de Quito. Dado el origen limeño de la séptima marquesa de Maenza, Mariana de Aranda, la familia de su marido quiteño, Gregorio Eugenio Matheu, mantuvo hasta el final de la época colonial relaciones con la capital del virreinato del Perú, hecho confirmado por el matrimonio de dos hijas suyas con destacados nobles limeños, Diego Suazo, de la orden

53 AC/Q, Matrimoniales, año 1803. 
nobiliaria de Santiago, y José Zapata Hurtado de Mendoza, conde de Cumbres Altas y antiguo oidor de la Audiencia de Quito. Mientras que las últimas dos parejas se radicaron en Lima, Juan Pío Montúfar y Frasso, igualmente oriundo del Perú y presidente de la Audiencia de Quito a partir de 1761, se casó en esta ciudad con una hija de la familia Larrea, enlace facilitado por una licencia real a causa de la avanzada edad del marqués. Fue el único alto funcionario real que se casó con una mujer de origen quiteño. ${ }^{54}$

A causa de la inmigración relativamente baja de la metrópoli durante la época colonial tardía, la cantidad de matrimonios entre miembros de la nobleza titulada y peninsulares fue también muy baja; hubo solamente cuatro con comerciantes españoles..$^{55}$

Los matrimonios tuvieron una importancia crucial para mantener o aumentar el patrimonio y el prestigio de una familia. La documentación que el cuarto marqués de Solanda, Diego Sánchez de Orellana, entregó a la Audiencia en 1789 solicitando una licencia real para poder contraer matrimonio con María Nicolasa Guerrero y Nájera, refleja todos los valores y requisitos según los cuales la alta nobleza quiteña evaluaba su propio rango social y elegía a sus cónyuges ${ }^{56}$ Puesto que los padres y abuelos de Diego eran ya difuntos, sus hermanas atestiguaron el consenso familiar ante la decisión de su hermano. Destacaron que María Nicolasa pertenecía a las familias más ilustres, antiguas y recomendables de la ciudad, entre cuyos ascendientes habían figurado los varones más esclarecidos y señalados en religión y piedad, en pureza de sangre, en empleos públicos y militares y en los muchos y muy grandes servicios en obsequio del rey y de la patria, razón por la cual el matrimonio era conforme al lustre, honor y decoro del título de Castilla. El padre de María Nicolasa, Pedro Guerrero y Ontañón, consintió en el matrimonio destacando las ilustres cualidades de esclarecida nobleza y empleos que adornaban la persona del referido señor marqués, y porque, poseyendo un mayorazgo de los más pingües de la ciudad, tenía con qué soportar las cargas del estado.

El factor económico más inmediato de los matrimonios fueron las arras y sobre todo la dote, con la cual fueron transferidas riquezas a veces

54 Véanse en cambio los vínculos matrimoniales considerablemente más estrechos entre la nobleza titulada y los funcionarios reales y sus familiares en Chile; Barbier, Jacques: "Elite and cadres in Bourbon Chile", Hispanic American Historical Review, LII:3, Durham, 1972, págs. 416-435.

55 Véase en cambio la mayor cantidad de matrimonios de la alta nobleza mexicana con peninsulares en Ladd, Doris M.: The Mexican nobility at Independence, 1780-1826, Austin, 1976.

56 Expediente que sigue el marqués de Solanda, solicitando licencia para contraer matrimonio con Doña Nicolasa Guerrero (...), ANE/Q, Matrimoniales, exp. 27-VII-1789, fols. 1v-3v. 
considerables entre generaciones y familias. Entre las grandes familias de la ciudad de Quito fue común, hasta la Independencia, proveer a las hijas con una dote que iba de 2.000 a 38.000 pesos, mientras que las arras que daba el novio oscilaban entre 2.000 y 10.000 pesos, el equivalente a la décima parte de sus bienes. ${ }^{57}$ Ambas partidas podían consistir en casas, haciendas, alhajas, indumentaria y dinero en efectivo, que a menudo fue invertido inmediatamente en la adquisición o el mejoramiento de una finca rural.

Puesto que la dote era solamente el pago adelantado de una parte de la herencia, los matrimonios llevaron consigo a veces la transferencia de otros bienes o títulos. Aparte de la ya mencionada sucesión del minero de Barbacoas, Pedro Quiñones y Cienfuegos, en el marquesado de Miraflores, se puede mencionar también el caso del mayorazgo de la familia Freire. Por el matrimonio de una heredera del mayorazgo, María Josefa Yerovi y Freire, con Francisco María de Larrea y Santa Coloma, en 1758, sucedió en el goce del vínculo su hija María Josefa, quien se casó con Joaquín Montúfar y Larrea, siendo ambos parientes consanguíneos en segundo grado. Cuando su hija, María Mercedes de Montúfar y Freire, contrajo matrimonio en 1818 con Mariano Miño y Valdés, rector y profesor de la universidad de Santo Tomás, tuvo que ceder ante la presión de una parte de su familia y dejar la sucesión a un pariente suyo, Ramón Borja y Villacís, puesto que la carta de fundación exigía que los cónyuges de los herederos del mayorazgo fueran hidalgos. Fue en vano el intento de Miño de demostrar con documentos su propia calidad de noble. ${ }^{58}$

La tendencia endogámica de la nobleza titulada de Quito fue acompañada de la formación de redes familiares que abarcaron campos sociales y económicos diferentes. ${ }^{59}$ Los testamentos y asientos notariales evidencian múltiples contactos que van desde poderes y fianzas hasta préstamos y negocios comunes. Un vínculo estrecho y constante existió por ejemplo entre Miguel de Jijón, primer conde de Casa Jijón, y Clemente Sánchez de

57 Las sumas indicadas se basan en 45 casamientos documentados en ANE/Q, Matrimoniales y Testamentarías.

58 Pruebas producidas por parte de don Ramón Borja y Villacís en causa que sigue con el doctor don Mariano Miño sobre la propiedad y pertenencia del mayorazgo de la hacienda de Cochasqui, ANE/Q, Vínculos y Mayorazgos, exp. 22-XI-1819; consulta del Consejo de Indias del 4 de mayo de 1819, AGI, Quito, 219.

59 La función de las redes familiares ha sido estudiada sistemáticamente para el caso hispanoamericano por Balmori, Diana, Stuart F. Voss y Miles Wortman: Notable family networks in Latin America, Chicago y Londres, 1984. 
Orellana, primer marqués de Villa Orellana. Durante sus largos viajes a Europa, el conde dejó la administración de todos sus negocios y propiedades en el distrito de la Audiencia de Quito a su pariente. ${ }^{60}$ Vínculos particularmente estrechos y múltiples existieron asimismo entre las familias Montúfar y Larrea.

Las redes familiares se manifestaron también en otros contextos sociales, por ejemplo en los testimonios con motivo de casamientos o pleitos. En 1786 José Román y Sánchez de Orellana se casó con Josefa Carcelén y Sánchez de Orellana, ambos parientes consanguíneos en tercer grado, en casa del cuarto marqués de Villa Rocha, José Carcelén; como padrinos asistieron el cuarto marqués de Solanda, Diego Sánchez de Orellana, y la primera marquesa de Villa Orellana, Javiera Chiriboga; testigos fueron Mariano Flores, segundo marqués de Miraflores, y Pedro Buendía Dávila, yerno del tercer marqués de Villa Rocha. ${ }^{61}$

\section{Status social y poder}

Las familias de la nobleza titulada de Quito formaron, junto con los cargos más altos de la jerarquía político-administrativa, eclesiástica y militar y algunas otras personas y familias criollas o peninsulares, la capa social alta, o sea la nobleza, durante la época colonial tardía. Por su prestigio, riqueza y función, la nobleza titulada fue considerada como el núcleo de la nobleza quiteña y, no obstante su diferenciación interna, se presentó como tal en las fiestas públicas, que proyectaban una imagen oficial e idealizada del orden social. ${ }^{62}$ Las familias de la alta nobleza quiteña fueron, por lo tanto, los agentes y representantes destacados de una mentalidad aristocrática que, coadyuvado con la economía poco dinámica de la región, logró conservar y fortalecer, hasta el final de la época colonial, una estructura

60 AMH/Q, n. ${ }^{\circ}$ 39, Demandas, Juicios, Testamentos de Quito (1788-1799), fol. 90; AHBC/Q, Documentos Particulares, núm. 644; véase Defourneaux, Marcelin: "Un ilustrado quiteño: Don Manuel [sic] Gijón y León, primer conde de Casa Jijón (1717-1794)”, Anuario de Estudios Americanos, 24, Sevilla, 1967, pág. 1240.

61 Moreno Egas, Jorge: "Resumen alfabético del segundo libro de matrimonios de españoles de la parroquia de el Sagrario de Quito 1764-1804", Revista del Centro Nacional de Investigaciones Genealógicas y Antropológicas, III, Quito, 1981, pág. 264.

62 Büschges, Christian: "Urban public festivals as representations and elements of social order in colonial Ecuador", en Observation and communication: The construction of realities in the Hispanic world, ed. por Tamar Herzog y Johannes-Michael Scholz, Francoforte/M., 1997, págs. 113-131. 
social jerárquica que se asemeja a las sociedades tradicionales del Antiguo Régimen europeo.

El hecho de que la nobleza titulada y en general la nobleza quiteña no gozaran de privilegios propios limita su carácter de estamento, que sin duda tenían por el prestigio social que atribuía la capa social alta a la ascendencia ilustre y al ejercicio de empleos de honor. ${ }^{63}$ Varios familiares de la alta nobleza quiteña mostraron además otro rasgo típico de las sociedades tradicionales de la Edad Moderna, es decir, la cristalización de rangos, o sea el ejercicio de varios cargos y funciones importantes en los campos social, económico y político-administrativo de la sociedad por una misma persona. ${ }^{64}$

No me parece razonable caracterizar a la nobleza titulada o a toda la capa social alta de Quito como una élite social o política, puesto que los conceptos modernos de élite acentúan normalmente la capacidad y la función específicas que distinguen a las élites y a sus integrantes de los otros grupos y estratos de la sociedad, que se definen sobre todo por su origen social, los privilegios o la riqueza de sus miembros. ${ }^{65}$

Respecto al término de élite política o al de oligarquía, ambos conceptos ligados al ejercicio de poder, quisiera expresar otras dudas o limitaciones acerca de su aplicabilidad para caracterizar a la nobleza titulada y a la capa social alta de Quito y de otras ciudades de la Hispanoamérica colonial. Existían sin duda muchas diferentes estructuras y mecanismos del poder que la nobleza quiteña, como también las otras capas sociales altas urbanas, sabían utilizar en su beneficio, por ejemplo por sus relaciones con los funcionarios reales locales o a través del cabildo. Sin embargo, la influencia de los quiteños, como la de los criollos americanos en general, sobre la política global fue muy restringida, por cuya razón se escuchaban, durante la época colonial tardía, voces que reclamaban abiertamente la participación activa de los criollos locales en la delineación de la política real,

63 Véase Büschges, Christian: "Las leyes del honor. Honor y estratificación social en el distrito de la Audiencia de Quito (siglo XVIII)", Revista de Indias, 57:209, Madrid, 1997, págs. 55-84.

64 Kocka, Jürgen: "Stand - Klasse - Organisation. Strukturen sozialer Ungleichheit in Deutschland vom späten 18. bis zum frühen 20. Jahrhundert", en Klassen in der europäischen Sozialgeschichte, ed. por Hans-Ulrich Wehler, Göttingen, 1979, pág. 140.

65 Véase por ejemplo Dreitzel, Hans P.: Elitebegriff und Sozialstruktur. Eine soziologische Begriffsanalyse, Stuttgart, 1962; Büschges, Christian: "Eugenio Espejo, la Ilustración y las Elites", Jahrbuch für Geschichte von Staat, Wirtschaft und Gesellschaft Lateinamerikas, 34, Colonia, Weimar y Viena, 1997 (en prensa); Maravall, José Antonio: Poder, honor y élites en el siglo XVII, Barcelona, 1989. Además Bush, M.L.: "An anatomy of nobility", en Social orders and social classes in Europe since 1500: Studies in social stratification, ed. por M.L. Bush, Londres y Nueva York, 1992, pág. 46. 
en cuanto que ésta afectaba directamente a los intereses y problemas de su respectiva región. ${ }^{66}$

La hora de la toma del poder vino finalmente, para los miembros de las capas sociales altas de Quito y de Hispanoamérica en general, con la crisis de la monarquía hispánica a partir de 1808 y la lucha por la independencia. Una vez que la independencia del distrito de la antigua Audiencia de Quito fue alcanzada por las tropas bolivarianas, bajo el mando de Antonio de Sucre en 1822, algunas de las familias más destacadas de la capa social alta de Quito lograron mantener su destacada posición social y ocupar puestos prominentes en la jerarquía política del siglo XIX, fenómeno bien conocido asimismo en otros países hispanoamericanos. ${ }^{67}$

66 McFarlane, Anthony: “The 'Rebellion of the Barrios': Urban Insurrection in Bourbon Quito", Hispanic American Historical Review, LXIX:2, Durham, 1989, págs. 283-330. Del mismo autor: "Civil disorders and popular protests in late colonial New Granada", Hispanic American Historical Review, LXIV:1, Durham, 1984, págs. 17-54.

67 Véase por ejemplo Stone, Samuel Z.: The heritage of the conquistadors. Ruling classes in Central America from the conquest to the Sandinistas, Lincoln y Londres, 1990. 